\title{
Aging during COVID-19 in Germany: A Longitudinal Analysis of Psychosocial Adaptation and Attitudes Toward Aging*
}

Anna Schlomann, Dr. ${ }^{1,2}$ Mareike Bünning, Dr. ${ }^{3}$ Lena Hipp, Dr. ${ }^{3,4}$ \& Hans-Werner Wahl, Dr. ${ }^{1,5}$

${ }^{1}$ Network Aging Research, Heidelberg University

${ }^{2}$ Mixed Methods Research, Heidelberg University of Education

${ }^{3}$ WZB Berlin Social Science Center, Berlin

${ }^{4}$ University of Potsdam

${ }^{5}$ Institute of Psychology, Heidelberg University

Anna Schlomann and Mareike Bünning contributed equally to this paper.

Key words: coronavirus pandemic, older adults, satisfaction with life, satisfaction with social relations, age stereotypes, survey study

Word count: 4,231 (excluding figures, and tables)

* Direct correspondence to Anna Schlomann, email: schlomann@ nar.uni-heidelberg.de. 


\begin{abstract}
Available theories of aging suggest that there may be similarities and differences in how COVID-19 impacts older peoples' psychosocial adaptation compared to younger age groups, particularly mid-aged individuals. We analyzed data from 3,215 participants between 40 and 79 years gathered at three measurement occasions between the start of the nation-wide lockdown mid-March 2020 and its lifting early August 2020 in an online survey in Germany. The survey focused on everyday experiences during the COVID-19 crisis and collected various satisfaction ratings (e.g., general life satisfaction, satisfaction with family life, satisfaction with social contacts). Participants also provided retrospective satisfaction ratings for their situations before the COVID-19 crisis at baseline. For a small sub-sample of 29 participants (48-78 years), we explored how attitudes toward own aging (ATOA) measured prior to the crisis may have played a role in satisfaction ratings during the crisis. Both mid-aged and older participants experienced the greatest decreases in satisfaction in the social domain, with more pronounced decreases seen in mid-aged participants. We also observed a partial recovery effect in all measures at T3, and this effect was more pronounced in older adults. More negative ATOA prior to the crisis was associated with lowered psychosocial adaptation. Although ageism arose during the pandemic in the sense that older adults were labeled as a "risk group" particularly at the outbreak, we found in accordance with other studies that midaged adults' satisfaction decreased to a greater extent than older adults'. Beginning evidence supports that attitudes toward aging were relevant for adaptation.
\end{abstract}

Keywords: coronavirus pandemic, older adults, satisfaction with life, satisfaction with social relations, age stereotypes, survey study 


\section{Aging during COVID-19 in Germany: A Longitudinal Analysis of Psychosocial}

\section{Adaptation and Attitudes Toward Aging}

As has been officially documented and reported across a large number of countries, older adults were the most severely affected of all age groups by the COVID-19 virus in terms of their health and lives (WHO 2020). However, not much is known on how the crisis has affected older adults' life satisfaction and psychological adaptation compared to other age groups, mid-aged adults, in particular. As older adults were negatively stereotyped as a "risk group" during the crisis due to their chronological age (Ayalon et al. 2020; Ehni and Wahl 2020; Jiminez-Sotomayor et al. 2020), it may well be that age stereotypes and perceptions of own aging prior to the COVID-19 crisis shaped psychological adaptation during the crisis.

\section{Psychosocial Challenges for Older Adults During the COVID-19 Crisis}

The SARS-CoV2 virus created an unexpectedly stressful situation for individuals around the globe, including community-dwelling older adults and those living in long-term care settings (Sands et al. 2020). This article looks at community-dwelling older adults. In Germany, where we conducted our study, older adults were affected by the crisis in at least four ways. First, data on mortality caused by COVID-19 infections were regularly communicated via the press and media; such reports clearly indicated that survival after medical treatment, such as ventilator treatment, was significantly lower for older adults (Wolf-Ostermann and Rothgang 2020).

Second, the ongoing discussion on the availability of intensive care beds (ICBs) and public communications on the possible need for triage in case of shortage of ICBs raised fears among older adults that, if infected, they would, not receive optimal medical treatment and would be accorded a lower priority predominantly due to their chronological age (Ehni and Wahl 2020). Television reports on the situation in other European countries - in particular, Italy, France, and Spain — suggested that age-driven triage may have been utilized due to ICB shortages. The inclusion of images of military trucks in Italy helping to cope with the 
exorbitant number of coffins might have further aroused such fears among older German adults (see also Cesari and Proietti 2020).

Third, the lockdown, which began in Germany in mid-March 2020, led to complete social isolation among older adults in nursing homes; but the same also largely applied to those living in the community. Many valuable activities for older adults, such as visiting or being visited by children and grandchildren, shopping, eating out, going to cultural events, hiking with peers, volunteering, or taking part in educational programs were out of the question. This separation from family and close others put older adults at risk of loneliness which may eventually also lead to physical and mental health decline (Tyrell and Williams 2020). At this point in time, was also unclear how long the situation would last.

Fourth, older adults faced ageism and negative age stereotyping in that they were seen as the major "risk group" who had to be protected by the lockdown and who had thus forced younger age groups to stay at home, minimize activity, and stop schooling, a development that had dramatic consequences for parents' lives and their childcare duties (Ayalon et al. 2020; Ehni and Wahl 2020).

Against this background, this paper addresses how mid-aged (40-64 years) and older adults (65-79 years) have psychologically adapted to the COVID-19 crisis in Germany covering a timespan with three measurement occasions from the point in time when the outbreak caused a country-wide lock-down to about 5 months later. We also explore the role of attitudes toward aging prior to the crisis to assess adaptation during the COVID-19 crisis.

\section{Conceptual Approach}

To conceptually capture the pandemic's psychosocial consequences, we draw on socio-emotional selectivity theory, stress and resilience theory, and age stereotype theory. First, socio-emotional selectivity theory (Carstensen 2006; English and Carstensen 2016; see also Martin 2020) argues that if time is perceived as limited, which is typically the case in old age and may have been reinforced by the COVID-19 crisis, people value emotionally 
meaningful relationships and goals more than other goals in life. This activates moodenhancing goals and reduces the willingness to accept temporary negative experiences for the sake of long-term benefits. Findings related to socio-emotional selectivity theory have informed a phenomenon referred to as the positivity effect of aging (Scheibe and Carstensen 2010). The positivity effect relates to a shifting ratio of paying attention to or remembering positive as opposed to negative information that occurs with advancing age.

A second theoretical lens through which to analyze the crisis's impact on individual well-being is stress theory (Lazarus 1993). The COVID-19 crisis represented a major physical and psychological health threat to populations worldwide, making coping and adaptational efforts necessary (Aravena et al. 2020). Recent research findings suggest that the COVID-19 pandemic caused various stress-related symptoms and anxiety for many people around the world (e.g., Casagrande et al. 2020; González-Sanguino et al. 2020). From a stress-theoretical view, it is important to note that the crisis came without warning and did not allow for anticipation and preparatory measures. Established stress research has shown that anticipation and prediction may increase feelings of control over stressors and thus reduce overall stress (Lazarus 1993). However, more recent work has also suggested that stress experiences in dayto-day life may increase "when you see it coming" (Neubauer et al. 2018). That said, the COVID-19 crisis may at least be partially similar to a natural disaster and may have similar consequences. This is relevant because there are findings suggesting that older adults exhibit higher resilience during natural disasters and have more positive outcomes than other age groups (Eshel et al. 2016; Rafiey et al. 2016; but see Parker et al., 2016 for opposing evidence). In addition, previous research on the so-called well-being paradox supports the notion that general life satisfaction is high in older adults and rather robust against stress experiences (Diehl et al. 2020; Kunzmann et al. 2000).

A third theoretical lens that may be useful in this case is age-stereotype theory. This conceptual approach allows us to analyze the adaptational outcomes of the COVID-19 crisis 
among middle-aged and older individuals, as older people are predominantly described as a "risk group" in public discourse, which may create negative age stereotypes in society due to chronological age along with negative self-perceptions of aging (see also Levy et al. 2020). Age-stereotype-related research has clearly shown that negative age stereotypes can be quickly triggered (Diehl et al. 2020; Wurm et al. 2017). Negative age stereotypes have been found to be three times more powerful in prompting negative effects than positive age stereotypes are in prompting positive effects (Meisner 2012). Furthermore, negative age stereotypes increase the risk of insomatic illnesses and functional impairment as well as undermining cognitive functioning and well-being (Wurm et al. 2017; Westerhof et al. 2014). For instance, negative age self-stereotyping has been implicated in inflammatory processes via C-reactive protein and has been found to lead to reinforced and raised cortisol secretions (Levy et al. 2000, 2016; Stephan et al. 2015). Such physiological pathways may increase the likelihood of cardiovascular disease and severe loss of cognitive performance in the long run. A recent study also supports the notion that negative perceptions of older age have increased the negative impact of the COVID-19 crisis among older people (Losada-Baltar et al. 2020).

\section{Hypotheses}

As suggested by the conceptual models applied to the COVID-19 crisis as outlined above, we examine two hypotheses relating to satisfaction ratings and explore the role of attitudes toward aging for psychological adaptation. First, by applying socio-emotional selectivity theory and the positivity effect to the COVID-19 crisis, we expected the crisis to have caused stronger decreases in satisfaction with social contact than in satisfaction with life in general among both middle-aged and older adults. Given the positivity effect in old age, we also expected the decreases in satisfaction with social contact to be more pronounced among middle-aged adults compared to older ones. Second, we expected a decrease in general life satisfaction as a result of the stress caused by the COVID-19 crisis that was of similar magnitude among both middle-aged and older adults. We also explored whether recovery 
effects occurred during the lockdown that followed the pandemic's outbreak in Germany as suggested by the psycho-adaptational literature on critical life events (Luhmann et al. 2012; Schilling and Wahl 2006). Third, we explored whether more negative attitudes toward aging were associated with lowered psychological adaptation both in middle-aged and older adults during the COVID-19 crisis.

\section{Research Design and Methods}

\section{Sample and Design}

In our analyses, we drew on three waves of survey data gathered in an online survey to capture individuals' everyday experiences during the COVID-19 lockdown in Germany ${ }^{1}$. The survey started one week after Germany went into a nationwide lockdown, which entailed closing schools, shops, restaurants, and businesses and prohibiting public gatherings. Participants learned about the study via email lists, newspaper announcements, and instant messenger services. Participants who agreed to be surveyed again were invited to participate in a follow-up survey 3.5 to 4 weeks after they completed the first questionnaire and again ten weeks after the first interview. The first wave of data collection ran between March 23, 2020 and May 11, 2020. The second wave of data collection (April 20 to June 14, 2020) coincided with the tentative lifting of the lockdown, including the limited re-openings of schools and shops. The third wave (June 3 to August 2, 2020) coincided with further liftings, including the decision to restart regular schooling after the summer holidays, and the government's presentation of its economic stimulus package.

The final sample size for the three survey waves amounted to 14,754 individuals in survey wave 1 (W1), 7,573 in wave 2 (W2) and 6,397 in wave 3 (W3). Our analytical sample included a total of 3,215 participants aged 40 to 79 years who participated in all three waves. More than $13 \%$ of the respondents in this sample $(\mathrm{N}=422)$ were aged between 65 and 79

\footnotetext{
${ }^{1}$ All data are available at https://doi.org/10.7802/2042
} 
years. Due to our theoretical interest, our analyses distinguished between mid-aged individuals (40-64 years) and older individuals (65-79 years). Besides the differences in chronological age between the two groups, the two groups differ substantially with regard to their labor force involvement and child and care activities. We excluded those 80 years and older due to the rather low sample size and the selectivity of "onliners" in this age category (see, for example, Schlomann et al. 2020).

As can be seen in Table 1, the majority of participants were female (72\%), partnered (73\%) and highly-educated (77\% of all participants had a university degree). In total, $85 \%$ of all participants were employed (age group 40-64: 93\%, age group 65-79: 26\%). Self-rated prepandemic physical health was 2.11 on a five-point scale in the whole sample. (Insert Table 1 about here)

The sociodemographic characteristics of individuals who participated in all three waves were very similar to those of the full W1 sample (see Table 1-Supplement). To assess respondents' situations before the COVID-19 crisis began, we included a couple of retrospective questions ( $\mathrm{t} 0$ ). To minimize inaccurate answering behaviors due to the high cognitive load of retrospective questions (Yan and Tourangeau 2007) and social desirability biases (Jaspers et al. 2009), we ensured that questions about the respondents' pasts were short, easy to understand, and referred to a specific anchor point (the prepandemic period) that was only a short time before the lockdown started (between two to six weeks). All of these factors have been shown to increase recall accuracy, even for subjective assessments such as ratings of health status and subjective well-being (Barsky 2002), and recall accuracy was found to be independent of respondents' age or educational background (Hipp et al. 2020).

For our additional exploratory analysis on the role of attitudes toward aging and their potential impact on psychosocial adaptation during the COVID-19 crisis, we invited participants of an ongoing longitudinal study on the role of views on aging and their connection with well-being and health outcomes to also participate in the online survey (see 
Rupprecht et al. 2019 for more information on the study). This longitudinal study has been running since 2012, and individuals have been surveyed at three measurement points, in 2012, 2015, and 2017. In total, of those invited, 29 participants also participated in all three waves of the online survey and provided a person-specific code that allowed to match the two data sources. The sample contained 16 participants aged over 65 years $(55 \%$, mean age: 64.2 years, $\mathrm{SD}=8.25$, age range: 48 to 78 years); $19(66 \%)$ were female, $18(62 \%)$ were partnered, and $20(69 \%)$ had a university degree.

\section{Measures}

Psychosocial Adaptation. Respondents were asked about their satisfaction (measured on a 7-point Likert scale) with family life, the quality of social contact (also via telephone, email etc.), and satisfaction with life in general. ${ }^{2}$ Although multi-item measurements are generally preferred, single-item measures are a commonly used and cost-effective method in survey research, and single-item measures of life satisfaction have been found to be reasonably valid (see Richter et al., 2017 for an overview).

Attitudes Toward Own Aging. Attitudes towards own aging (ATOA), which were only collected for the small subsample of participants who participated in both studies (e.g., Rupprecht et al. 2019), were based on the respective Attitudes Toward Own Aging subscale of the Philadelphia Geriatric Morale Scale (Brothers et al. 2019; Lawton, 1975). The ATOA is among the most established scales in the subjective aging field internationally (Diehl et al. 2014). We used a person-specific mean value across the measurement waves in 2012, 2015, and 2017 as a proxy for a time-constant individual difference variable in ATOA. Respondents answered 5 items such as "Things keep getting worse as I get older" or "I am as happy now as

\footnotetext{
${ }^{2}$ Additionally, we also collected respondents' satisfaction with work (among the employed), their relationship and their division of household labor (among partnered persons), as well as satisfaction with neighborhood solidarity. In this paper, however, our focus is on the social domain and on satisfaction with life in general.
} 
when I was younger" in a dichotomous way whether they agree (yes $=1)$ or not $($ no $=0)$. Higher values indicate a more positive perception of own aging.

Covariates. The following covariates were included in the multivariate analyses: gender (female/male), presence of partner in the household (dummy), level of education (dummy variable indicating university degree), whether the person was working (dummy), self-reported physical health prior to the pandemic (1 item, 5-point Likert scale, adapted from the German Socio-Economic Panel), and the size of respondents' place of residence (greater/lesser than 50,000). Presence of a partner and employment status were assessed in each wave; the remaining variables were assessed at $\mathrm{t} 1$.

\section{Data Analysis}

The survey data were analyzed using OLS regressions with clustered, robust standard errors using four time points ( $\mathrm{t} 0$ (retrospective assessment) to $\mathrm{t} 3$ ). To test whether the coefficients significantly differed by age group and time point, we included interaction effects for age and time point. In the ATOA substudy, we assessed satisfaction ratings across time points in a primarily descriptive way depending on a group median split in ATOA due to the small number of participants. We also applied a nonparametric Kruskal-Wallis procedure as an exploratory statistical test of differences across time between individuals high versus low in ATOA.

\section{Results}

We start by presenting mean levels of all satisfaction ratings across the four time points separately for the two age groups (Figure 1). Satisfaction ratings decreased in both age groups for general life satisfaction and for family life and quality of social contact at the beginning of the pandemic and recovered to some extent at the last observation period. (Insert Figure 1 about here)

\section{Psychosocial Adaptation Across Time}


Findings from the OLS regressions are summarized in Table 2. Respondents from both age groups reported significantly higher levels of satisfaction with life in general, family life, and the quality of social contacts before the beginning of the pandemic (t0) than during the first weeks of lockdown (reference category).

Comparing the size of the coefficients between age groups, we found decreases in general life satisfaction and satisfaction with the quality of social contact. These decreases, however, were more pronounced among middle-aged adults than older adults. In fact, coefficients were almost twice as high in the middle-aged group, and the differences in the size of the coefficients were statistically significant (see Table 2 -Supplement). Satisfaction with family life, by contrast, decreased to a similar extent in both age groups.

Comparing the changes in satisfaction across different areas of life, we found that decreases in satisfaction with contact quality were most pronounced in both age groups. Among mid-aged respondents, decreases in general life satisfaction came second, followed by decreases in satisfaction with family life, whereas older respondents' satisfaction with both areas decreased to a similar extent (see Table 4-Supplement).

In addition, there was little evidence of recovery at $\mathrm{t} 2$ (in the middle of the lockdown period) compared to 11 . On the contrary, older respondents' satisfaction with all three life domains tended to deteriorate further, as did middle-aged respondents' satisfaction with social contacts. Only middle-aged respondents' satisfaction with life in general slightly recovered, whereas their satisfaction with family life remained stable. Yet, we observed partial recovery towards the end of the lockdown (hence approximately four months after the start of the lockdown). Although both older and mid-aged respondents reported higher levels of life satisfaction and satisfaction with family and social contacts at $\mathrm{t} 3$ compared to $\mathrm{t} 1$, older adults had a stronger recovery in general life satisfaction and satisfaction with social contacts than mid-aged adults when comparing their ratings at $\mathrm{t} 3$ to the prepandemic period $(\mathrm{t} 0)$. Recovery in satisfaction with family life was similar for both age groups (see Table 3-Supplement). 
Note, however, that satisfaction ratings in all three dimensions remained considerably below the prepandemic levels.

\section{Exploring the Role of Attitudes Toward Aging Prior to the Corona Crisis for}

\section{Psycosocial Adaptation}

The findings of our small-scale explorative analysis indicated that ATOA prior to the COVID-19 crisis indeed played a role in psychological adaptation during the pandemic. As can be seen in Figure 2, satisfaction levels with family life, quality of social contact, and life in general were consistently lower among those with a more negative prepandemic ATOA. Furthermore, ATOA seems to be related to changes in satisfaction ratings. Ratings for satisfaction with life in general converged between the two groups in the course of the pandemic and ratings of satisfaction with the quality of social contacts diverged, with lower ratings among those with a more negative ATOA. Satisfaction with family life first converged until $\mathrm{t} 2$ but became more different between the two groups at $\mathrm{t} 3$ (see Figure 2). However, findings based on a Kruskal-Wallis test indicated no significant difference at any time point in any satisfaction domain between the two groups, although this may be due to our underpowered sample.

(Insert Figure 2 about here)

\section{Discussion}

This study explored differences in satisfaction with social life and life in general between mid-aged individuals (40 to 64 years) and older individuals (65 to 79 years) during the COVID-19 pandemic in Germany. Based on an online survey with more than 3,000 respondents, we found that psychological adaptation to the COVID-19 pandemic differed to some extent between mid-aged and older individuals and that the reactions to the lockdown were contingent on the satisfaction domain as well as age and attitudes toward own aging.

In line with our first hypothesis, we observed the most pronounced decreases in satisfaction with the quality of social contacts and that the decrease was more pronounced 
among mid-aged than older adults. In addition, the recovery in satisfaction ratings towards the end of the lockdown was stronger among older adults. This finding is in line with other studies on the age-specific impact of the COVID-19 crisis. In their analyses of the German Socio-Economic Panel, for instance, Entringer and Kröger (2020) found an increase in loneliness among both younger and older age groups but that the increase was less pronounced among older adults. Similar results were found for the United States (Luchetti et al. 2020) and the United Kingdom (Bu et al. $2020 \mathrm{a}$, b); in these studies, however, the comparison group was younger (18 to 29 years) than in our study (40 to 64 years).

These findings suggest that the positivity effect as described by socio-emotional selectivity theory (Carstensen 2006; English and Carstensen 2016) may have protected older adults from experiencing or suffering from social isolation to some extent. Older adults tend to process negative information (such as the pandemic) less intensive as younger individuals due to their reduced future time perspective and may unfold a stronger tendency to emphasize positive side effects related to COVID-19 as well as generally. In addition, older adults' higher psychosocial resilience to COVID-19-like challenges may result from accumulated life experiences (Staudinger 1999) and their higher flexibility in downsizing social aspirations (Brandtstädter 2006); both processes may lead to higher satisfaction even in a disadvantageous social situation.

In accordance with our second hypothesis, we also found decreases in general life satisfaction among both mid-aged (40 to 64 years) and older participants (65 to 79 years) compared to before the crisis ( $\mathrm{t} 1$ to $\mathrm{t} 0$ ). Again, the decrease was more pronounced among mid-aged adults. Besides the aforementioned explanations referring to positivity and resilience-like factors (Eshel et al. 2016; Rafiey et al. 2016), the established well-being paradox in old age, also labeled the "stability despite loss" paradigm (Kunzmann et al. 2000) may add to explaining the age-differential impact of the COVID-19 crisis on general life satisfaction. 
An important feature of our research design was the inclusion of a second and third measurement point during the lockdown period in Germany. Interestingly, we observed no recovery in any satisfaction domain between $\mathrm{t} 1$ and $\mathrm{t} 2$. Satisfaction with the quality of social contacts even deteriorated further across both age groups during the early months of the lockdowns. We only observed some recovery for both age groups and across life domains at $\mathrm{t} 3$, hence about 4-5 months after baseline, but satisfaction ratings still remained below prepandemic levels.

Finally, our small-scale explorative analysis provided preliminary evidence on whether attitudes toward one's own aging prior to the crisis was a potentially protective or a risk-enhancing individual-difference variable. As has also been found in prior research (Losada-Baltar et al. 2020), satisfaction levels tended to be lower among those with a more negative pre-pandemic ATOA and there were also different trajectories in the two groups of positive versus negative ATOA across time.

A number of limitations of this study need to be noted. First, although we included a broad range of covariates in our analyses to address the fact that our data came from a nonprobability online survey and different sociodemographic groups varied in their likelihood to participate, our estimates may nonetheless be biased with regard to education, gender, and the usage of the technology necessary for an online study, in particular. Second, our analyses only included community-dwelling older adults, who experienced much less dramatic social consequences during the lockdown than those in long-term care institutions. Thus, we have not addressed the very high-risk constellation that affected those living in nursing homes (European Centre for Disease Prevention and Control 2020). Moreover, we did not include individuals aged 80 years and older in order to avoid further selection biases Yet, it would be very important to also consider adults in nursing homes and of very old age in future COVID19 studies on psychosocial adaptation due their very different physical and mental ability and thus their reduced resource status (Baltes and Smith 2003). Third, our findings with regard to 
the respondents' retrospective assessments of their pre-pandemic well-being (t0) should also be interpreted cautiously. Despite the fact that asking retrospective question has been increasingly used to expand the backward lifespan in surveys on mid-aged and older adults (Börsch-Supan and Schröder 2011), retrospective assessment continues to be under debate in its measurement quality due to their proneness for inaccuracies and answering biases (Jürges 2007). In the case of this study, however, our results are most likely to be conservative, as research on retrospective questions during COVID-19 found that respondents tend to remember their past as more similar to their present (and not more idealized) when the experience or feeling of interest has changed between the time of the interview and the time point of interest, (Hipp et al. 2020). Finally, a bigger sample for explorative analysis targeting the role of attitudes toward own aging is needed in future research, although our results seem to be in line with at least one other study (Losada-Baltar et al. 2020).

In conclusion, although ageism in the form of labeling older adults as "the risk group" occurred during the pandemic and might have caused psychological harm (Ayalon et al. 2020; Ehni and Wahl 2020), the current study found that both middle-aged and old-age individuals experienced decreases in a number of satisfaction ratings. However, in accordance with other large longitudinal studies, the decreases were more pronounced in middle-aged adults than in older adults. Furthermore, older adults showed a larger extent of recovery in the general domain and for satisfaction with quality of social contacts compared to middle-aged adults. Some initial evidence also suggested that more negative ATOA undermined psychological adaptation during the COVID-19 crisis, which fits well with the now robust evidence that more negative views of one's aging are a considerable risk for the maintenance of mental and physical health. 


\section{References}

Aravena JM, Aceituno C, Nyhan K, Shi S, Vermund S, Levy BR (2020) Drawing on wisdom to cope with adversity:' A systematic review protocol of older adults' mental and psychosocial health during acute respiratory disease propagated-type epidemics and pandemics (COVID-19, SARS-CoV, MERS, and Influenza). Preprint, medRxiv. https://doi.org/10.1101/2020.06.04.20122812

Ayalon L, Chasteen A, Diehl M, Levy B, Neupert SD, Rothermund K, Tesch-Römer C, Wahl, H-W (2020) Aging in times of the COVID-19 pandemic: Avoiding ageism and fostering intergenerational solidarity. J Gerontol B Psychol Sci Soc Sci. Editorial (Online published only). https://doi.org/10.1093/geronb/gbaa051

Baltes PB, Smith J (2003) New frontiers in the future of aging: From successful aging of the young old to the dilemmas of the fourth age. Gerontology 49:123-35. https://doi.org/10.1159/000067946

Barsky AJ (2002) Forgetting, fabricating, and telescoping. Arch Intern Med 162(9):981-984. https://doi.org/10.1001/archinte.162.9.981

Börsch-Supan M, Schröder M (2011) Retrospective Data Collection in the Survey of Health, Ageing and Retirement in Europe. SHARELIFE Methodology: 5-10.

Brandtstädter J (2006) Action perspectives on human development. In: Damon W, Lerner RM (eds) Handbook of child psychology: Vol. 1. Theoretical models of human development, $6^{\text {th }}$ ed. Wiley, New York, pp 516-568.

Brothers A, Gabrian M, Diehl M, Wahl H-W (2019) Measuring awareness of age-related change (AARC): A new multidimensional questionnaire to assess positive and negative subjective aging in adulthood. Gerontologist 59:e141-e151. https://doi.org/10.1093/geront/gny006 
Bu F, Steptoe A, Fancourt D (2020a) Loneliness during lockdown: trajectories and predictors during the COVID-19 pandemic in 35,712 adults in the UK. Preprint, medRxiv. https://doi.org/10.1101/2020.05.29.20116657

Bu F, Steptoe A, Fancourt D (2020b) Who is lonely in lockdown? Cross-cohort analyses of predictors of loneliness before and during the COVID-19 pandemic. Preprint, medRxiv. https://doi.org/10.1101/2020.05.14.20101360

Carstensen LL (2006) The influence of a sense of time on human development. Science 30:1913-1915. https://doi.org/10.1126/science.1127488

Casagrande M, Favieri F, Tambelli R, Forte G (2020) The enemy who sealed the world: Effects quarantine due to the COVID-19 on sleep quality, anxiety, and psychological distress in the Italian population. Sleep Med 75:12-20. https://doi.org/10.1016/j.sleep.2020.05.011

Cesari M, Proietti M (2020) Geriatric medicine in Italy in the time of COVID-19. Editorial. J Nutr Health Aging 24:1-2. https://doi.org/10.1007/s12603-020-1354-z

Diehl M, Wahl H-W, Barrett AE, Brothers AF, Miche M, Montepare JM, Westerhof GJ, Wurm S (2014) Awareness of aging: Theoretical considerations on an emerging concept. Dev Rev, 34(2):93-113. http://dx.doi.org/10.1016/j.dr.2014.01.001

Diehl M, Brothers AF, Wahl H-W (2020) Self-perceptions and awareness of aging: Past, present, and future. In: Schaie KW, Willis SL (eds) Handbook of the psychology of aging, 8th edition (forthcoming). Elsevier, New York.

Ehni HJ, Wahl H-W (2020) Six propositions against ageism in the COVID-19 pandemic. J Aging Soc Policy 4-5:515-525. https://doi.org/10.1080/08959420.2020.1770032

English T, Carstensen LL (2016) Socioemotional selectivity theory. In: Pachana N (ed) Encyclopedia of geropsychology. Springer Online, New York. https://doi.org/10.1007/978-981-287-080-3_110-1 
Entringer TM, Kröger H (2020) Einsam, aber resilient - Die Menschen haben den Lockdown besser verkraftet als vermutet [Lonely but resilient - People have coped with the lockdown better than expected] (Paper No. 46). DIW Berlin, German Institute for Economic Research. http://hdl.handle.net/10419/222876. Accessed 24 September 2020

Eshel Y, Kimhi S, Lahad M, Leykin D (2016) Individual, community, and national resiliencies and age: Are older people less resilient than younger individuals? Am J Geriatr Psychiatry 24(8):644-647. https://doi.org/10.1016/j.jagp.2016.03.002.

European Centre for Disease Prevention and Control (2020) Surveillance of COVID-19 at long-term care facilities in the EU/EEA. Technical Report. https://www.ecdc.europa.eu/sites/default/files/documents/COVID-19-long-term-carefacilities-surveillance-guidance.pdf. Accessed 24 June 2020.

González-Sanguino C, Ausín B, Ángel Castellanos M, Saiz J, López-Gómez A, Ugidos C, Muñoz M (2020) Mental health consequences during the initial stage of the 2020 Coronavirus pandemic (COVID-19) in Spain. Brain Behav Immun 87:172-176. https://doi.org/10.1016/j.bbi.2020.05.040.

Hipp L, Bünning M, Munnes S, Sauermann A (2020) Problems and pitfalls of retrospective survey questions in COVID-19 studies. Surv Res Methods 14:109-114. https://doi.org/10.18148/srm/2020.v14i2.7741

Jaspers E, Lubbers M, Graaf NDD (2009) Measuring once twice: An evaluation of recalling attitudes in survey research. Eur Sociol Rev 25(3):287-301. https://doi.org/10.1093/esr/jcn048

Jiminez-Sotomayor MR, Gomez-Moreno C, Soto-Perez-de-Celis E (2020) Coronavirus, ageism, and Twitter: An evaluation of Tweets about older adults and COVID-19. J Am Geriatr Soc 68(8). Brief Report. Published online. https://doi.org/10.1111/jgs.16508 
Jürges H (2007) Unemployment, Life Satisfaction, and Retrospective Error. J R Stat Soc Ser A Stat Soc 170(1):43-61.

Kunzmann U, Little TD, Smith J (2000) Is age-related stability of subjective well-being a paradox? Cross-sectional and longitudinal evidence from the Berlin Aging Study. Psychol Aging 15:511-526. https://doi.org/10.1037/0882-7974.15.3.511

Lawton MP (1975) The Philadelphia Geriatric Center Morale Scale: A revision. J Gerontol 30:85-89. https://doi.org/10.1093/geronj/30.1.85

Lazarus RS (1993) Coping theory and research: Past, present, and future. Psychosom Med 55:234-247. https://doi.org/10.1097/00006842-199305000-00002

Levy BR, Hausdorff JM, Hencke R, Wei, JY (2000) Reducing cardiovascular stress with positive self-stereotypes on aging. J Gerontol B Psychol Sci Soc Sci 55(4):P205-P213. https://doi.org/10.1093/geronb/55.4.P205

Levy BR, Ferrucci L, Zonderman AB, Slade MD, Troncoso J, Resnick SM (2016) A culturebrain link: Negative age stereotypes predict Alzheimer's disease biomarkers. Psychol Aging 31:82-88. https://doi.org/10.1037/pag0000062

Levy BR, Slade MD, Chang E, Kannoth S, Wang S (2020) Ageism amplifies cost and prevalence of health conditions. Gerontologist 60:174-181. https://doi.org/10.1093/geront/gny131

Losada-Baltar A, Jimenez-Gonzalo L, Gallego-Alberto L, Pedroso-Chaparro M, FernandesPires J, Marquez-Gonzalez M (2020) "We're staying at home": Association of selfperceptions of aging, personal and family resources and loneliness with psychological distress during the lockdown period of COVID-19. J Gerontol B Psychol Sci Soc Sci. Published online. https://doi.org/10.1093/geronb/gbaa048

Luchetti M, Lee JH, Aschwanden D, Sesker A, Strickhouser JE, Terracciano A, Sutin AR (2020) The trajectory of loneliness in response to COVID-19. Am Psychol. Advance online publication. https://doi.org/10.1037/amp0000690 
Luhmann M, Hofmann W, Eid M, Lucas RE (2012) Subjective well-being and adaptation to life events: A meta-analysis. J Pers Soc Psychol 102(3):592-615. https://doi.org/10.1037/a0025948

Martin P (2020) The Effect of a Virus on Adult Development. J Adult Dev 27:81-82. https://doi.org/10.1007/s10804-020-09353-1

Meisner BA (2012) A meta-analysis of positive and negative age stereotype priming effects on behavior among older adults. J Gerontol B Psychol Sci Soc Sci 67:13-17. https://doi.org/10.1093/geronb/gbr062.

Neubauer AB, Smyth JM, Sliwinski MJ (2018) When you see it coming: Stressor anticipation modulates stress effects on negative affect. Emotion 18(3):342-354. https://doi.org/10.1037/emo0000381

Parker G, Lie D, Siskind DJ et al (2016) Mental health implications for older adults after natural disasters - a systematic review and meta-analysis. Int Psychogeriatr 28(1):1120. https://doi.org/10.1017/S1041610215001210.

Rafiey H, Momtaz YA, Alipour F, et al (2016) Are older people more vulnerable to long-term impacts of disasters? Clin Interv Aging 11:1791-1795. https://doi.org/10.2147/CIA.S122122

Richter D, Rohrer J, Metzing M, Nestler W, Weinhardt M, Schupp J (2017) SOEP Scales Manual (updated for SOEP-Core v32.1). SOEP Survey Papers 423: Series C. Berlin: DIW/SOEP https://www.diw.de/documents/publikationen/73/diw_01.c.571151.de/ diw_ssp0423.pdf

Rupprecht FS, Dutt AJ, Wahl H-W, Diehl M (2019) The role of personality in becoming aware of age-related changes. GeroPsych, 32(2), 57-67. https://doi.org/10.1024/16629647/a000204

Sands LP, Albert SM, Suitor JJ (2020) Understanding and addressing older adults' needs during COVID-19. Innov Aging 4(3). https://doi.org/10.1093/geroni/igaa019 
Scheibe S, Carstensen LL (2010) Emotional aging: recent findings and future trends. J Gerontol B Psychol Sci Soc Sci 65:135-44. https://doi.org/10.1093/geronb/gbp132

Schilling O, Wahl H-W (2006) Modeling late life adaptation in affective well-being under a severe chronic health condition: The case of age-related macular degeneration. Psychol Aging 21:703-714. https://doi.org/10.1037/0882-7974.21.4.703

Schlomann A, Seifert A, Zank S, Woopen C, Rietz C (2020) Use of ICT Devices among the Oldest-Old: Loneliness, Anomie, and Autonomy. Innov Aging 4(2). https://doi.org/10.1093/geroni/igz050.

Staudinger UM (1999) Older and wiser? Integrating results from a psychological approach to the study of wisdom. Int J Behav Dev 23:641-664. https://doi.org/10.1080/016502599383739

Stephan Y, Sutin AR, Terracciano A (2015) Younger subjective age is associated with lower C-reactive protein among older adults. Brain Behav Immun 43:33-36. https://doi.org/10.1016/j.bbi.2014.07.019

Tyrrell CJ, Williams KN (2020) The paradox of social distancing: Implications for older adults in the context of COVID-19. Psychol Trauma 12(S1):S214-S216. https://doi.org/10.1037/tra0000845

Westerhof GJ, Miche M, Brothers AF, Barrett AE, Diehl M, Montepare JM, Wahl H-W, Wurm S (2014) The influence of subjective aging on health and longevity: A metaanalysis of longitudinal data. Psychol Aging 29:793-802. https://doi.org/10.1037/a0038016.

Wolf-Ostermann K, Rothgang H (2020) Zur Situation der Langzeitpflege in Deutschland während der Corona-Pandemie [Situation of long-term care in Germany during the Corona pandemic]. Report published online https://www.unibremen.de/fileadmin/user_upload/ fachbereiche/fb11/Aktuelles/Corona/ 
Ergebnisbericht_Coronabefragung_Uni-Bremen_24062020.pdf. Accessed 24

September 2020

World Health Organization (WHO) (2020). WHO Director-General's opening remarks at the media briefing on COVID-19, March 11, 2020.

https://www.who.int/dg/speeches/detail/who-director-general-s-opening-remarks-atthe-media-briefing-on-covid-19---11-march-2020. Accessed 20 July 2020.

Wurm S, Diehl M, Kornadt AE, Westerhof GJ, Wahl H-W (2017) How do views on aging affect health outcomes in adulthood and late life? Explanations for an established connection. Dev Review 46:27-43. https://doi.org/10.1016/j.dr.2017.08.002 02732297

Yan T, Tourangeau R (2007) Fast times and easy questions: The effects of age, experience and question complexity on web survey response times. Appl Cogn Psychol 22(1):5168. https://doi.org/10.1002/acp.1331 
Table 1: Descriptive Statistics (at t1)

\begin{tabular}{|c|c|c|c|c|c|c|c|c|c|}
\hline & \multicolumn{2}{|l|}{ All } & \multicolumn{3}{|c|}{ Age 40-64 } & \multicolumn{3}{|c|}{ Age $65-79$} & \multirow[b]{2}{*}{$\mathrm{N}$} \\
\hline & mean & $\mathrm{sd}$ & $\mathrm{N}$ & mean & $\mathrm{sd}$ & $\mathrm{N}$ & mean & $\mathrm{sd}$ & \\
\hline Age $65-79$ & 0.13 & 0.34 & 3215 & & & & & & \\
\hline Women & 0.72 & 0.45 & 3185 & 0.74 & 0.44 & 2763 & 0.58 & 0.49 & 422 \\
\hline Partnered & 0.73 & 0.44 & 3186 & 0.74 & 0.44 & 2771 & 0.68 & 0.47 & 415 \\
\hline University degree & 0.77 & 0.42 & 3175 & 0.77 & 0.42 & 2762 & 0.75 & 0.43 & 413 \\
\hline Working & 0.85 & 0.36 & 3128 & 0.93 & 0.25 & 2732 & 0.26 & 0.44 & 396 \\
\hline Self-rated pre-pandemic physical health ${ }^{\mathrm{a}}$ & 2.11 & 0.82 & 3205 & 2.11 & 0.81 & 2785 & 2.10 & 0.84 & 420 \\
\hline Townsize $>50000$ inhabitants & 0.68 & 0.47 & 3197 & 0.69 & 0.46 & 2777 & 0.61 & 0.49 & 420 \\
\hline$N$ & 3215 & & & 2793 & & & 422 & & \\
\hline
\end{tabular}

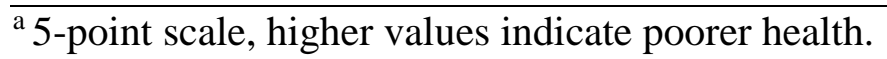


Table 2: OLS Regressions on Satisfaction with Different Domains of Life Using t1 as Reference

\begin{tabular}{lcccccc}
\hline & Life & & Family & \multicolumn{3}{c}{ Contacts } \\
& $40-64$ & $65-79$ & $40-64$ & $65-79$ & $40-64$ & $65-79$ \\
\hline t0 & $0.75^{* * * *}$ & $0.44^{* * *}$ & $0.54^{* * *}$ & $0.50^{* * *}$ & $1.34^{* * *}$ & $0.75^{* * *}$ \\
& {$[0.70,0.80]$} & {$[0.34,0.54]$} & {$[0.48,0.59]$} & {$[0.37,0.63]$} & {$[1.27,1.41]$} & {$[0.61,0.90]$} \\
t2 & $0.05^{*}$ & -0.10 & -0.03 & -0.18 & $-0.16^{* * *}$ & $-0.27^{* *}$ \\
t3 & {$[0.00,0.10]$} & {$[-0.25,0.06]$} & {$[-0.09,0.02]$} & {$[-0.36,0.01]$} & {$[-0.22,-0.09]$} & {$[-0.44,-0.10]$} \\
& $0.29^{* * *}$ & $0.21^{* *}$ & $0.19^{* * *}$ & $0.24^{* *}$ & $0.29^{* * * *}$ & 0.17 \\
Women & {$[0.23,0.34]$} & {$[0.05,0.36]$} & {$[0.13,0.25]$} & {$[0.06,0.41]$} & {$[0.22,0.35]$} & {$[-0.00,0.33]$} \\
& $-0.12^{* * *}$ & -0.06 & -0.05 & -0.22 & $0.11^{*}$ & 0.07 \\
Partnered & {$[-0.21,-0.04]$} & {$[-0.25,0.13]$} & {$[-0.15,0.04]$} & {$[-0.44,0.00]$} & {$[0.01,0.20]$} & {$[-0.15,0.29]$} \\
& $0.21^{* * * *}$ & 0.05 & $0.52^{* * *}$ & $0.39^{* *}$ & $-0.27^{* * *}$ & $-0.35^{* *}$ \\
University degree & {$[0.13,0.30]$} & {$[-0.15,0.26]$} & {$[0.42,0.63]$} & {$[0.14,0.64]$} & {$[-0.36,-0.17]$} & {$[-0.59,-0.10]$} \\
& 0.05 & -0.05 & -0.00 & -0.11 & -0.09 & -0.09 \\
Working & {$[-0.05,0.14]$} & {$[-0.27,0.16]$} & {$[-0.11,0.10]$} & {$[-0.36,0.13]$} & {$[-0.19,0.01]$} & {$[-0.33,0.15]$} \\
& $0.19^{*}$ & -0.16 & 0.07 & -0.14 & 0.14 & -0.00 \\
Health & {$[0.02,0.35]$} & {$[-0.35,0.03]$} & {$[-0.10,0.25]$} & {$[-0.37,0.09]$} & {$[-0.03,0.31]$} & {$[-0.21,0.20]$} \\
& $-0.39^{* * *}$ & $-0.28^{* * *}$ & $-0.35^{* * *}$ & $-0.24^{* * *}$ & $-0.18^{* * * *}$ & $-0.16^{*}$ \\
Town size $>50000$ & {$[-0.44,-0.34]$} & {$[-0.39,-0.17]$} & {$[-0.40,-0.29]$} & {$[-0.38,-0.11]$} & {$[-0.23,-0.12]$} & {$[-0.28,-0.03]$} \\
& $-0.11^{*}$ & -0.07 & $-0.10^{*}$ & 0.01 & $-0.10^{*}$ & 0.00 \\
Constant & {$[-0.19,-0.02]$} & {$[-0.27,0.12]$} & {$[-0.20,-0.01]$} & {$[-0.22,0.24]$} & {$[-0.20,-0.01]$} & {$[-0.22,0.22]$} \\
& $5.75^{* * *}$ & $6.44^{* * *}$ & $5.58^{* * *}$ & $5.99^{* * *}$ & $5.04^{* * * *}$ & $5.86^{* * *}$ \\
& {$[5.47,6.03]$} & {$[5.92,6.96]$} & {$[5.28,5.87]$} & {$[5.38,6.60]$} & {$[4.76,5.33]$} & {$[5.25,6.48]$} \\
\hline N(persons) & 2747 & 411 & 2746 & 409 & 2747 & 411 \\
N(observations) & 10529 & 1533 & 10381 & 1510 & 10531 & 1538 \\
R2 & 0.12 & 0.07 & 0.09 & 0.08 & 0.14 & 0.09 \\
\hline
\end{tabular}

Note: Coefficients stem from OLS regressions with clustered, robust standard errors; confidence intervals provided in parentheses. ${ }^{*} p<0.05,{ }^{* *} p<0.01,{ }^{* * *} p<0.001$ 
Figure 1: Sample Means of Satisfaction Ratings by Age Group and Measurement Occasion

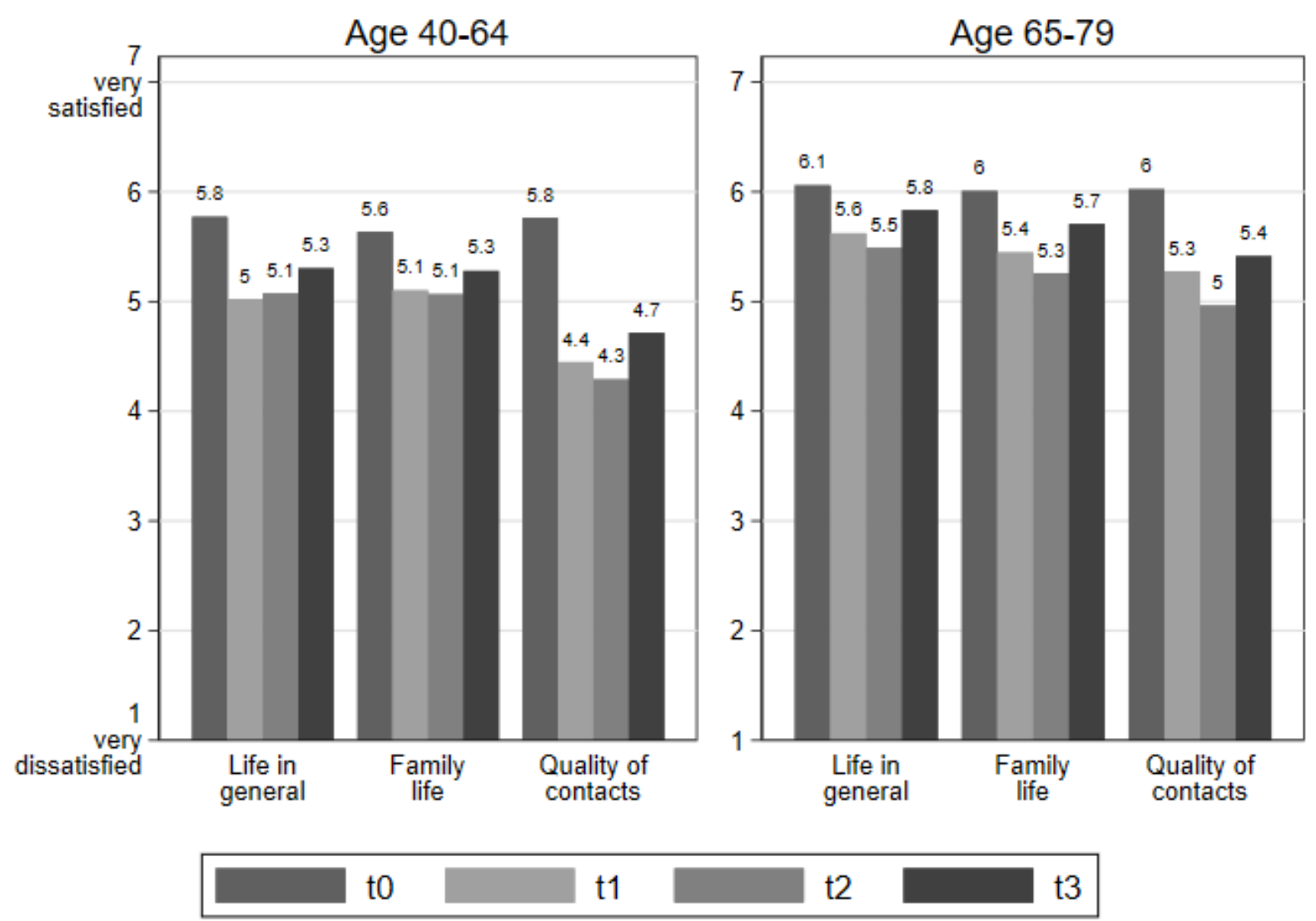

Note: Mean values for satisfaction ratings across time; $\mathrm{t} 0$ : retrospective assessment of pre-pandemic situation assessed at $\mathrm{t} 1$, $\mathrm{t} 1$ : assessed March 23 to May 11, 2020, t2: assessed 3.5 to 4 weeks after t1 (April 20 to June 14, 2020), t3: assessed 10 weeks after t1 (June 3 to August 20, 2020). 
Figure 2: Explorative Analysis: Satisfaction Ratings across Measurement Occasions Depending on Attitudes Toward Own Aging (ATOA) Prior to the COVID-19 Crisis

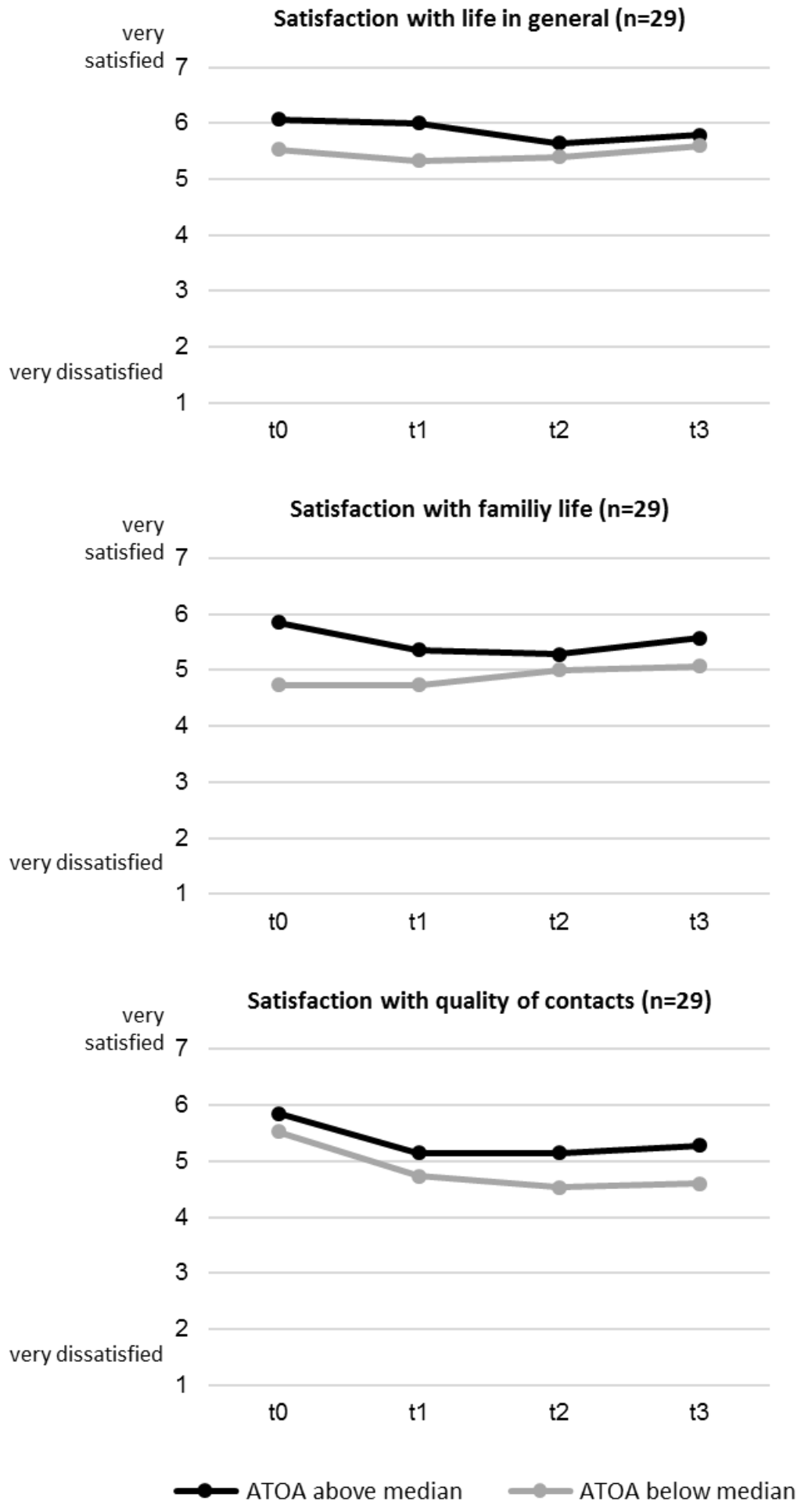

Note: Mean values for satisfaction ratings across time; $t 0$ : retrospective assessment of prepandemic situation assessed at t1, t1: assessed March 23 to May 11, 2020, t2: assessed 3.5 to 4 weeks after t1 (April 20 to June 14, 2020), t3: assessed 10 weeks after t1 (June 3 to August 20, 2020). 
Supplementary Data 
Table 1-Supplement: Selectivity of Sample W1-W3 compared to full W1 Sample

\begin{tabular}{lrrrrrr}
\hline & \multicolumn{2}{c}{ Participants Wave 1 } & \multicolumn{3}{c}{ Participants Wave 1 to 3 } \\
& mean & sd & $\mathrm{N}$ & mean & sd & $\mathrm{N}$ \\
\hline Age 65-79 & 0.11 & 0.31 & 6660 & 0.13 & 0.34 & 3215 \\
Women & 0.69 & 0.46 & 6573 & 0.72 & 0.45 & 3185 \\
Partnered & 0.73 & 0.44 & 6569 & 0.73 & 0.44 & 3186 \\
University degree & 0.74 & 0.44 & 6520 & 0.77 & 0.42 & 3175 \\
Working & 0.87 & 0.34 & 6417 & 0.85 & 0.36 & 3128 \\
Self-rated pre-pandemic physical health & 2.12 & 0.82 & 5254 & 2.11 & 0.82 & 3205 \\
Townsize >50000 inhabitants & 0.65 & 0.48 & 6604 & 0.68 & 0.47 & 3197 \\
\hline$N$ & 6660 & & & 3215 & & \\
\hline
\end{tabular}


Table 2-Supplement: OLS Regressions on Satisfaction with Different Domains of Life Using t 1 as Reference: Pooled model

\begin{tabular}{|c|c|c|c|}
\hline & Life & Family & Contacts \\
\hline \multirow[t]{2}{*}{ Age $65-79$} & $0.66^{* * *}$ & $0.43^{* * *}$ & $0.89^{* * *}$ \\
\hline & {$[0.48,0.83]$} & {$[0.23,0.63]$} & {$[0.70,1.08]$} \\
\hline \multirow[t]{2}{*}{$\mathrm{t} 0$} & $0.75^{* * *}$ & $0.54^{* * *}$ & $1.34^{* * *}$ \\
\hline & {$[0.70,0.81]$} & {$[0.48,0.59]$} & {$[1.27,1.41]$} \\
\hline \multirow[t]{2}{*}{$\mathrm{t} 2$} & $0.05^{*}$ & -0.03 & $-0.16^{* * *}$ \\
\hline & {$[0.00,0.10]$} & {$[-0.09,0.02]$} & {$[-0.22,-0.09]$} \\
\hline \multirow[t]{2}{*}{$\mathrm{t} 3$} & $0.29^{* * *}$ & $0.19^{* * *}$ & $0.29^{* * * *}$ \\
\hline & {$[0.23,0.34]$} & {$[0.13,0.25]$} & {$[0.22,0.35]$} \\
\hline \multirow[t]{2}{*}{ t0 $*$ Age $65-79$} & $-0.32^{* * * *}$ & -0.04 & $-0.59^{* * *}$ \\
\hline & {$[-0.43,-0.20]$} & {$[-0.18,0.10]$} & {$[-0.75,-0.43]$} \\
\hline \multirow[t]{2}{*}{$\mathrm{t} 2 *$ Age $65-79$} & -0.14 & -0.15 & -0.12 \\
\hline & $\begin{array}{c}{[-0.31,0.02]} \\
-0.08\end{array}$ & $\begin{array}{c}{[-0.34,0.04]} \\
0.05\end{array}$ & $\begin{array}{c}{[-0.30,0.06]} \\
-0.12\end{array}$ \\
\hline t3 $*$ Age $65-79$ & {$[-0.24,0.08]$} & {$[-0.14,0.23]$} & {$[-0.30,0.06]$} \\
\hline \multirow[t]{2}{*}{ Women } & $-0.11^{* *}$ & -0.07 & $0.11^{*}$ \\
\hline & {$[-0.18,-0.03]$} & {$[-0.16,0.01]$} & {$[0.02,0.19]$} \\
\hline \multirow[t]{2}{*}{ Partnered } & $0.19^{* * *}$ & $0.51^{* * *}$ & $-0.28^{* * *}$ \\
\hline & {$[0.11,0.27]$} & {$[0.42,0.61]$} & {$[-0.37,-0.19]$} \\
\hline \multirow[t]{2}{*}{ University degree } & 0.03 & -0.02 & $-0.09^{*}$ \\
\hline & {$[-0.06,0.12]$} & {$[-0.12,0.08]$} & {$[-0.19,-0.00]$} \\
\hline \multirow[t]{2}{*}{ Working } & 0.08 & 0.01 & 0.10 \\
\hline & {$[-0.05,0.21]$} & {$[-0.13,0.15]$} & {$[-0.04,0.23]$} \\
\hline \multirow[t]{2}{*}{ Health } & $-0.38^{* * *}$ & $-0.33^{* * *}$ & $-0.18^{* * *}$ \\
\hline & {$[-0.43,-0.33]$} & {$[-0.39,-0.28]$} & {$[-0.22,-0.13]$} \\
\hline \multirow[t]{2}{*}{ Town size $>50000$} & $-0.10^{*}$ & -0.08 & $-0.09^{*}$ \\
\hline & {$[-0.18,-0.02]$} & {$[-0.17,0.00]$} & {$[-0.17,-0.00]$} \\
\hline \multirow[t]{2}{*}{ Constant } & $5.84^{* * *}$ & $5.62^{* * * *}$ & $5.07^{* * * *}$ \\
\hline & {$[5.59,6.08]$} & {$[5.36,5.89]$} & {$[4.81,5.32]$} \\
\hline $\mathrm{N}($ persons $)$ & 3155 & 3152 & 3155 \\
\hline $\mathrm{N}$ (observations) & 12062 & 11891 & 12069 \\
\hline $\mathrm{R} 2$ & 0.12 & 0.09 & 0.15 \\
\hline
\end{tabular}

Note: Coefficients stem from OLS regressions with clustered, robust standard errors; confidence intervals provided in parentheses. $\mathrm{T}$

${ }^{*} p<0.05,{ }^{* *} p<0.01,{ }^{* * *} p<0.001$ 
Table 3-Supplement: OLS Regressions on Satisfaction with Different Domains of Life Using to as Reference: Pooled model

\begin{tabular}{lccc}
\hline & Life & Family & Contacts \\
\hline Age 65-79 & $0.34^{* * * *}$ & $0.39^{* * *}$ & $0.30^{* * * *}$ \\
& {$[0.19,0.49]$} & {$[0.22,0.56]$} & {$[0.15,0.45]$} \\
t1 & $-0.75^{* * *}$ & $-0.54^{* * *}$ & $-1.34^{* * *}$ \\
& {$[-0.81,-0.70]$} & {$[-0.59,-0.48]$} & {$[-1.41,-1.27]$} \\
t2 & $-0.71^{* * *}$ & $-0.57^{* * *}$ & $-1.50^{* * *}$ \\
& {$[-0.76,-0.65]$} & {$[-0.63,-0.51]$} & {$[-1.57,-1.43]$} \\
t3 & $-0.47^{* * *}$ & $-0.35^{* * *}$ & $-1.06^{* * *}$ \\
& {$[-0.52,-0.42]$} & {$[-0.40,-0.30]$} & {$[-1.12,-0.99]$} \\
t1 * Age 65-79 & $0.32^{* * *}$ & 0.04 & $0.59^{* * * *}$ \\
& {$[0.20,0.43]$} & {$[-0.10,0.18]$} & {$[0.43,0.75]$} \\
t2 * Age 65-79 & $0.17^{*}$ & -0.11 & $0.47^{* * *}$ \\
& {$[0.01,0.34]$} & {$[-0.29,0.07]$} & {$[0.28,0.66]$} \\
t3 * Age 65-79 & $0.24^{* *}$ & 0.09 & $0.47^{* * *}$ \\
& {$[0.09,0.39]$} & {$[-0.07,0.25]$} & {$[0.31,0.64]$} \\
\hline N(persons) & 3155 & 3152 & 3155 \\
N(observations) & 12062 & 11891 & 12069 \\
R2 & 0.12 & 0.09 & 0.15 \\
\hline
\end{tabular}

Note: Coefficients stem from OLS regressions with clustered, robust standard errors; confidence intervals provided in parentheses. The models additionally include gender, partnership status, employment status, health and size of place of residence.

${ }^{*} p<0.05,{ }^{* *} p<0.01,{ }^{* * *} p<0.001$ 
Table 4-Supplement: Comparison of Coefficients across Measurement Occasions and Life Domain by Age Groups

\begin{tabular}{|c|c|c|c|c|}
\hline & \multicolumn{2}{|c|}{40 to 64 yrs. } & \multicolumn{2}{|c|}{65 to 79 yrs. } \\
\hline & $\chi^{2}$ & p-value & $\chi^{2}$ & p-value \\
\hline \multicolumn{5}{|l|}{ to vs. t1 } \\
\hline Life vs. family satisfaction & 62.67 & 0.00 & 0.79 & 0.37 \\
\hline Life vs. contact quality satisfaction & 338.06 & 0.00 & 20.47 & 0.00 \\
\hline Family vs. contact quality satisfaction & 442.68 & 0.00 & 9.80 & 0.00 \\
\hline \multicolumn{5}{|l|}{ t1 vs. $\mathbf{t} 2$} \\
\hline Life vs. family satisfaction & 7.63 & 0.01 & 1.09 & 0.30 \\
\hline Life vs. contact quality satisfaction & 40.10 & 0.00 & 4.87 & 0.03 \\
\hline Family vs. contact quality satisfaction & 11.96 & 0.00 & 1.26 & 0.26 \\
\hline \multicolumn{5}{|l|}{ t1 vs. $\mathbf{t 3}$} \\
\hline Life vs. family satisfaction & 11.69 & 0.00 & 0.15 & 0.70 \\
\hline Life vs. contact quality satisfaction & 0.00 & 0.96 & 0.23 & 0.63 \\
\hline Family vs. contact quality satisfaction & 6.36 & 0.01 & 0.63 & 0.43 \\
\hline
\end{tabular}

Note: Stata's suest command was used to compare regression coefficients across life domains and time points (taken from Table 2). 